Discussion Paper No. 02-65

Comparison Between Unitary and Collective Models of Household Labor Supply With Taxation

Denis Beninger and François Laisney

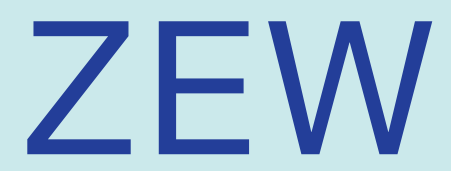

Zentrum für Europäische Wirtschaftsforschung GmbH

Centre for European

Economic Research 
Discussion Paper No. 02-65

\title{
Comparison Between Unitary and Collective Models of Household Labor Supply With Taxation
}

\author{
Denis Beninger and François Laisney
}

Download this ZEW Discussion Paper from our ftp server:

ftp://ftp.zew.de/pub/zew-docs/dp/dp0265.pdf

Die Discussion Papers dienen einer möglichst schnellen Verbreitung von neueren Forschungsarbeiten des ZEW. Die Beiträge liegen in alleiniger Verantwortung der Autoren und stellen nicht notwendigerweise die Meinung des ZEW dar.

Discussion Papers are intended to make results of ZEW research promptly available to other economists in order to encourage discussion and suggestions for revisions. The authors are solely responsible for the contents which do not necessarily represent the opinion of the ZEW. 


\section{Non-technical summary}

Collective models of household consumption and labor supply behavior allow the representation of individual behavior inside the household. By contrast, the more widely used unitary models consider household behavior as resulting from the decisions of a single individual, occulting the fact that most households are composed of several individuals who take part in the decision processes, and thus precluding the analysis of intra-familial redistribution of household resources. For a model of allocation of leisure and consumption of an aggregate good, Chiappori $(1988,1992)$ has shown that simply assuming Pareto efficient allocations implies a set of restrictions on the labor supply functions, and that these are sufficient to identify the individual preferences and an income sharing rule up to an additive constant. The basic model has been extended in several directions, including household production and children, and the presence of more than two decision makers in the household. Empirically relevant discrete decisions, such as non participation of one of the household's members, introduce further difficulties. Even in that case, complete identification (up to an additive constant) has been shown for collective models with a convex budget set.

Yet vast research efforts remain necessary for the implementation of collective models in all situations where unitary models are used in practice, in particular in the presence of non-convex budget sets, and for modeling intertemporal allocations. The aim of the present study is to assess the potential returns of such a research program, by comparing collective and unitary models on the basis of simulated collective data with income taxation. By simulating data from the collective model we circumvent the difficulties that are still connected with its estimation, but we are able to point out the many distortions created by the use of a unitary model. We focus on the analysis of tax reforms because this type of exercise often motivates the estimation of household preference parameters. We distinguish the cases of individual and joint taxation. Estimating the unitary model we obtain strikingly different 'preference' parameters depending on the type of taxation. We also obtain substantial differences between predicted adjustments to labor supply following a switch between tax regimes, and hence potentially wide-ranging definitions of revenue-neutral versions of tax reforms: our results show that even the design of revenue-neutral reforms may be heavily distorted by the use of a unitary model on collective data. Finally we discuss distortions affecting the welfare analysis of reforms on the basis of unitary estimates when the model generating the data is a collective model. The results suggest that increased efforts should be devoted to the estimation of collective models with taxation. 


\title{
Comparison between unitary and collective models of household labor supply with taxation
}

\author{
Denis Beninger* and François Laisney ${ }^{\dagger}$
}

October 2002

\begin{abstract}
Several recent papers have shown the relevance of collective models for the empirical investigation of household labor supply and consumption. Yet the estimation of collective models in the presence of non-linear budget sets and participation decisions remains a daunting task. This paper compares collective and unitary models on the basis of simulated collective data with income taxation. We distinguish the cases of individual and joint taxation. Estimating the unitary model we obtain strikingly different 'preference' parameters depending on the type of taxation. We also obtain substantial differences between predicted adjustments to labor supply following a switch between tax regimes, and hence potentially wide-ranging definitions of revenue-neutral versions of tax reforms. Finally we discuss distortions affecting the welfare analysis of reforms on the basis of unitary estimates when the model generating the data is a collective model. The results suggest that increased efforts should be devoted to the estimation of collective models with taxation.
\end{abstract}

Key words: Pareto optimal allocation, tax reform, simulated data JEL Codes: D11, D12

Acknowledgments: We are grateful to Pierre-André Chiappori, Isabelle Maret, Hubert Stahn, Frederic Vermeulen and Elke Wolf for careful reading of a preliminary version. All errors remain our own.

\footnotetext{
*Zentrum für Europäische Wirtschaftsforschung (ZEW), L7 1, D-68161 Mannheim, Germany.

${ }^{\dagger}$ BETA-THEME, Université Louis Pasteur, 61 avenue de la Forêt-Noire, F-67000 Strasbourg, France, and ZEW.
} 


\section{Introduction}

Collective models of household consumption and labor supply behavior, introduced by Chiappori (1988, 1992) and Apps and Rees (1988), allow the representation of individual behavior inside the household. By contrast, the more widely used unitary models consider household behavior as resulting from the decisions of a single individual, occulting the fact that most households are composed of several individuals who take part in the decision processes. This precludes the analysis of intra-familial redistribution of household resources. Unitary models treat the family as a black box, so that the income distribution inside the family cannot be reconstructed (see e.g. Lechene, 1993). The main difficulty with the unitary models concerns aggregation of preferences (see Arrow, 1951 and Hildenbrand, 1994) and of individual demands (see Deaton and Muellbauer, 1980). Although Samuelson's consensus idea (1956) and Becker's altruistic model (1991) generate consensual behavior for as regards resource allocation within the family, the underlying assumptions have been criticized as highly restrictive (see e.g. Ben Porath, 1982, and Bergstrom, 1989); indeed allocations within the household may well be conflictual (see Sen, 1984).

For a model of allocation of leisure and consumption of an aggregate good, Chiappori $(1988,1992)$ shows that his definition of collective rationality, which imposes Pareto efficient allocations, implies a set of restrictions on the labor supply functions, and that these are sufficient to identify the individual preferences and the income sharing rule up to an additive constant. These conditions consist in a set of restrictions on the partial differentials of the labor supply functions .

The basic model has been extended in several directions, including household production and children (Apps and Rees, 1996, 1997, 1999, Chiappori, 1997, Chiuri, 1999 and Bourguignon, 1999), and the presence of more than two decision makers in the household (Browning and Chiappori, 1998). Empirically relevant discrete decisions, such as non participation of one of the household's members, introduce further difficulties. Even in that case, complete identification (up to an additive constant) has been shown for collective models with a linear budget constraint (Blundell et al., 1998) and with a convex budget set (Donni, 2000, and Beninger, 2000). More details concerning the literature on collective models can be found in the excellent survey of Vermeulen (2002).

Yet vast research efforts remain necessary for the implementation of collective models in all situations where unitary models are used in practice, in particular in the presence of non-convex budget sets, and for modeling intertemporal allocations. The aim of the present study is to assess the 
potential returns of such a research program: by simulating data from the collective model we circumvent the difficulties that are still connected with its estimation, but we are able to point out the many distortions created by the use of a unitary model. The reason why we do not perform the symmetric exercise of simulating unitary data and analyzing distortions from the use of collective is twofold. Firstly, as already mentioned, estimating a collective will be difficult (unless we take into account the fact that the data have been generated by a unitary model), and secondly, it is the unitary model which is regularly rejected in the empirical literature, and this in itself justifies our asymmetric treatment. We focus on the analysis of tax reforms because this type of exercise often motivates the estimation of household preference parameters. Our results show that even the design of revenue-neutral reforms may be heavily distorted by the use of a unitary model on collective data.

In Section 2, we briefly present the two models. In Section 3 we explain how the simulated data sets are generated, and these are described in Section 4. The econometric specification of the estimated unitary model, which draws on van Soest (1995) is discussed in Section 5. Estimation and policy simulation results are discussed in Section 6, with four subsections presenting the estimates, their use in predicting labor supplies, and the positive and normative analysis of tax reforms, respectively.

\section{The representation of household behavior}

In this section we briefly present unitary and collective models of allocation of leisure and consumption of an aggregate good at the household level.

\section{$2.1 \quad$ Unitary models}

Unitary models assume that the household maximizes a unique utility function, independent of prices and incomes. They also assume the pooling of family incomes. Thus, for these models, the allocations are deduced from the maximization of a utility function under budget and time constraints:

$$
\left\{\begin{array}{l}
\max _{c_{f}, l_{f}, c_{m}, l_{m}} U\left(c_{f}, l_{f}, c_{m}, l_{m}\right), \\
c_{f}+c_{m} \leq g\left(l_{f}, l_{m}, w_{f}, w_{m}, y\right), \\
0 \leq T-l_{i} \leq H \quad \forall i=f, m,
\end{array}\right.
$$

where $c_{i}, l_{i}, w_{i}, y, H$ and $T$ represent respectively $i$ 's $(i=f, m$, for wife and husband, respectively) consumption, leisure demand and gross wage rate, the couple's unearned income, the maximum work time and the total time in a 
week. ${ }^{1}$ Function $g($.$) , which describes the tax system, is assumed to generate$ convex budget sets. ${ }^{2}$ The utility function $U($.$) is increasing in its arguments$ and quasi-concave.

With the unitary model, the intra-household distribution of resources plays no role. Yet the question of intra-familial redistribution of incomes can be crucial in determining household choices (see e.g. Lundberg et al., 1996) and answers are important if institutions want to conduct efficient and fair economic and social policies (see e.g. Haddad and Kanbur, 1990). Collective models can offer such answers.

\subsection{Collective models}

In these models, consumptions choices are derived by assuming only Paretooptimality of allocations, and this single a priori assumption defines the collective rationality concept used. Following Chiappori (1988), we focus on the case where individuals' preferences are egoistic (each spouse's utility is only defined on own consumption and leisure). In that case, and for a linear household budget restriction, household behavior can be represented sequentially, using an explicit sharing rule for the unearned income. Chiappori shows that individual preferences and the sharing rule are identified from observable behavior, up to a constant. The extension to the case of non linear, but convex, budget sets has been introduced by Donni (2000): for egoistic individuals the individual preferences and the unearned income sharing rule can still be identified up to an additive constant. ${ }^{3}$

In the case of egoistic preferences, collective models with convex budget sets have the following centralized representation:

$$
\left\{\begin{array}{l}
\max _{c_{f}, l_{f}, c_{m}, l_{m}} U^{f}\left(c_{f}, l_{f}\right)+\lambda(.) U^{m}\left(c_{m}, l_{m}\right), \\
c_{f}+c_{m} \leq g\left(l_{f}, l_{m}, w_{f}, w_{m}, y\right) \\
0 \leq T-l_{i} \leq H \quad \forall i=f, m
\end{array}\right.
$$

where $\lambda()=.\lambda\left(w_{f}, w_{m}, y\right)$ represents the relative weight of the husband. ${ }^{4}$ Alternatively, the sequential representation is: ${ }^{5}$

\footnotetext{
${ }^{1}$ The maximum number of hours of work was introduced for numerical reasons, but it could be justified by the existence of legal constraints.

${ }^{2}$ While this restriction can easily be relaxed for the unitary model, this is not (yet) the case for the collective model.

${ }^{3}$ See also Beninger (2000).

${ }^{4}$ If $\lambda$ is constant, model (2) is a special case of a unitary model, with separability in the partition $\left(c_{f}, l_{f}\right),\left(c_{m}, l_{m}\right)$.

${ }^{5}$ See Chiappori, 1992 and Apps and Rees, 1988, for the linear case, and Donni, 2000, for the convex case.
} 


$$
\left\{\begin{array}{l}
\max _{c_{i}, l_{i}} U^{i}\left(c_{i}, l_{i}\right), \\
c_{i} \leq \tilde{w}_{i}\left(T-l_{i}\right)+\tilde{y}_{i}, \\
0 \leq T-l_{i} \leq H \quad \forall i=f, m,
\end{array}\right.
$$

where $\tilde{w}_{i}$ is $i$ 's implicit (or shadow) wage at the optimum $\left(c_{f}^{*}, l_{f}^{*}, c_{m}^{*}, l_{m}^{*}\right)$ :

$$
\tilde{w}_{i}=g_{l_{i}}\left(l_{f}^{*}, l_{m}^{*}, w_{f}, w_{m}, y\right)
$$

with $g_{x}=\partial g / \partial x$. If we define the household's implicit unearned income, $\tilde{y}$, as:

$$
\tilde{y}=g\left(l_{f}^{*}, l_{m}^{*}, w_{f}, w_{m}, y\right)-\sum_{i=f, m} \tilde{w}_{i}\left(T-l_{i}^{*}\right),
$$

there exists an implicit income sharing rule which determines $\tilde{y}_{f}$ as $\tilde{y}_{f}=$ $\tilde{\Upsilon}\left(\tilde{w}_{f}, \tilde{w}_{m}, \tilde{y}\right)$, such that the sequential representation (3) is equivalent to the centralized form (4) of the model. The equivalence can be shown with the implicit functions theorem.

In our simulations, the implicit income sharing rule $\tilde{\Upsilon}($.) will be related to the effective sharing rule which the spouses use to share gross unearned income. This sharing rule is defined as

$$
\Upsilon:\left(w_{f}, w_{m}, y\right) \longmapsto y_{f} / y
$$

where $y_{f}$ denotes the wife's share of gross unearned income.

\section{Simulation of collective data}

Data were generated from the following specification of the sequential representation (3) of the collective model: ${ }^{6}$

$$
\left\{\begin{array}{l}
\max _{c_{i}, l_{i}} U^{i}\left(c_{i}, l_{i}\right), \\
c_{i} \leq g_{i}\left(l_{f}, l_{m}, w_{f}, w_{m}, y\right), \\
0 \leq T-l_{i} \leq H \quad \forall i=f, m,
\end{array}\right.
$$

where $g_{i}\left(l_{f}, l_{m}, w_{f}, w_{m}, y\right) \equiv \tilde{w}_{i}\left(T-l_{i}\right)+\tilde{y}_{i}$. The chosen functional form for the individual utility functions is:

$$
U^{i}\left(c_{i}, l_{i}\right)=k_{i} \log \left(c_{i}-\bar{c}\right)+\left(1-k_{i}\right) \log l_{i},
$$

\footnotetext{
${ }^{6}$ The justification for preferring the sequential representation in this exercise is that it computationally simpler, especially for the cases of absence of taxation and of individual taxation, described later in this section.
} 
where $k_{i}$ denotes the marginal propensity to consume, and $\bar{c}$ is a minimum level of consumption, assumed identical for all individuals. ${ }^{7}$

To describe precisely how the simulations were done, we need to explain how all variables and parameters needed to compute optimal allocations on the basis of (7) and (8) are generated or set, and to specify the budget constraints $g_{i}$. Parameter settings and variable generation are described in Appendix A.

In order to specify the budget constraint in (7), we first define the sharing rule for gross unearned income (equation (6)). We assume that gross unearned income is shared in proportion to gross wages:

$$
\Upsilon\left(w_{f}, w_{m}, y\right)=\frac{y_{f}}{y}=\frac{w_{f}}{w_{f}+w_{m}} .
$$

This choice is motivated, with drastic simplifications, by results from several empirical studies (see e.g. Bourguignon et al., 1994). Refining the sharing rule by letting it depend on actual unearned incomes would probably strengthen the distortions due to the use of the unitary representation, because of its implication of income pooling. However it turns out that the simple choice made here suffices to produce evidence of substantial distortions. Another refinement that would increase distortions would make the sharing rule explicitly depend on the tax system. This kind of approach is taken up in the papers gathered in Laisney (2002).

Next we turn to the tax system. In the absence of taxation (linear budget constraint), we have:

$$
g_{i}(.)=w_{i}\left(T-l_{i}\right)+y_{i}, \quad \forall i=f, m .
$$

In the case of personal taxation (each spouse taxed individually) with a piece-wise linear progressive tax schedule, $i$ 's disposable income $(i=f, m)$ is:

$$
g_{i}^{p}(.)=\sum_{k=1}^{s-1}\left(1-\tau_{p}^{k}\right)\left(S_{p}^{k+1}-S_{p}^{k}\right)+\left(1-\tau_{p}^{s}\right)\left(R_{i}^{p}-S_{p}^{s}\right),
$$

where $R_{i}^{p}$ is $i$ 's gross income: $R_{i}^{p}=w_{i} .\left(T-l_{i}^{p}\right)+y_{i}$. Vector $\tau_{p}=\left(\tau_{p}^{1}, \ldots, \tau_{p}^{t_{p}}\right)$ is the vector of marginal tax rates and $S_{p}=\left(S_{p}^{1}, \ldots, S_{p}^{t_{p}}\right)$ is the corresponding vector of tax brackets for individual taxation. There are $t_{p}$ tax brackets and $s$ represents the bracket for which $S_{p}^{s} \leq R_{i}^{p}<S_{p}^{s+1}$ if $s<t_{q}$ and $S_{p}^{s} \leq R_{i}^{p}$ if $s=t_{p}$. In that case, the assumptions made imply complete separation of the problems solved by the two spouses.

\footnotetext{
${ }^{7}$ Without the introduction of $\bar{c}$, preferences would be homothetic, a restriction which is universally empirically rejected.
} 
In the case of common or joint taxation with a piece-wise linear progressive taxation rule, $i$ 's disposable income is:

$$
g_{i}^{c}(.)=w_{i}\left(T-l_{i}^{c}\right)+y_{i}-I_{i}^{c}, \quad \forall i=f, m,
$$

where $I_{i}^{c}$ is $i$ 's contribution to the total tax liability $I^{c}$ of the household, where the latter is given by:

$$
I^{c}(.)=\sum_{k=1}^{s-1} \tau_{c}^{k}\left(S_{c}^{k+1}-S_{c}^{k}\right)+\tau_{c}^{s}\left(R^{c}-S_{c}^{s}\right),
$$

where $R^{c}=\sum_{i} w_{i} .\left(T-l_{i}^{c}\right)+y$ is household gross income and the notations for the tax brackets and marginal tax rates are similar to the case of personal taxation. We assume that the tax liability of the household is shared proportionately to gross incomes, i.e. $I_{i}^{c} / I^{c}=R_{i}^{c} / R^{c}$. This assumption is arbitrary but it is the most convenient rule we could think of.

The numerical values we choose for the tax parameters are: $\tau_{p}=\tau_{c}=$ $(0, .3, .5), S_{p}=(0,5000,10000)$ and $S_{c}=(0,7800,15000)$, so as to ensure revenue neutrality (approximately). ${ }^{8}$

The collective model thus defined is perfectly deterministic. It is not clear to us whether or not this feature systematically puts the unitary model in a more disadvantageous situation than if some noise had been introduced in the model.

\section{Simulated collective data sets}

We have generated data for 2000 couples in three different cases: no taxation, joint taxation and individual taxation. Each individual is characterized by an observed heterogeneity factor, the marginal propensity to consume, and has a budget constraint $g_{i}\left(l_{f}, l_{m}, w_{f}, w_{m}, y\right)$ which depends on the tax system and on the sharing rule $\Upsilon$ and has as arguments both leisure demands, both gross wage rates and household unearned income. ${ }^{9}$ Given these functions, the optimal labor supply and consumption of each spouse is computed for each tax situation by solving (7) for each household, with real-valued solutions, using Mathematica 4.0. A summary of the results is given in Table 1, and a more complete description is given in Appendix B.

\footnotetext{
${ }^{8}$ All magnitude pertain to a week, except the hourly wage rate.

${ }^{9}$ Sine we have drawn the wages of husband and wife independently, there is no assortative mating in these data sets.
} 
Table 1: Simulated data (means)

\begin{tabular}{lrrrr}
\hline \hline variable & symbol & no tax. & joint tax. & indiv. tax. \\
\hline her work hours & $h_{f}$ & 46.8 & 39.6 & 42.8 \\
his work hours & $h_{m}$ & 45.8 & 38.6 & 40.7 \\
household cons. & $c$ & 13,730 & 10,695 & 11,026 \\
\hline her wage & $w_{f}$ & & 77.3 & \\
his wage & $w_{m}$ & & 102.3 & \\
unearned income & $y$ & & 5,054 & \\
\hline
\end{tabular}

Regardless of the tax situation, the wife's labor supply, $h_{f}$, is on average a little higher than the husband's, $h_{m}$. This is not what is observed for childless couples in typical data sets, and a more complex specification of the sharing rule, or the specification of different preferences for males and females, would probably allow us to come up with simulated data more closely mimicking established stylized facts. Note that here the only difference between husbands and wives is that men have on average higher wages, which translates into a higher share of unearned income, and thus into lower labor supply, given that leisure is a normal good in the preferences considered.

When the individuals are not taxed, women are more likely to prefer a part-time job (about 20 hours weekly), or to work overtime. Men are slightly more likely to work an 'average' number of hours (30 to 40 weekly hours). But despite the wage differential, the distribution of labor supply is roughly the same for both sexes. Compared to real data for most countries, labor supply here is rather high, with a majority of individuals working between 30 and 70 hours per week. About 7\% do not participate: these are essentially individuals with a high level of unearned income. individuals with a high marginal propensity to consume are under-represented among non participants.

The introduction of taxation has a large disincentive impact, but this varies with individual and household characteristics. individuals with high wages and high unearned income are more affected, while the poorest are not affected at all.

In the specific case of the introduction of individual taxation, consider two identical women (same marginal propensity to consume, same wage and household unearned income), but assume that their husbands are endowed with different wages. The woman whose husband has the lower wage supports a larger disincentive effect than the other one, because of the specification of the income sharing rule. 

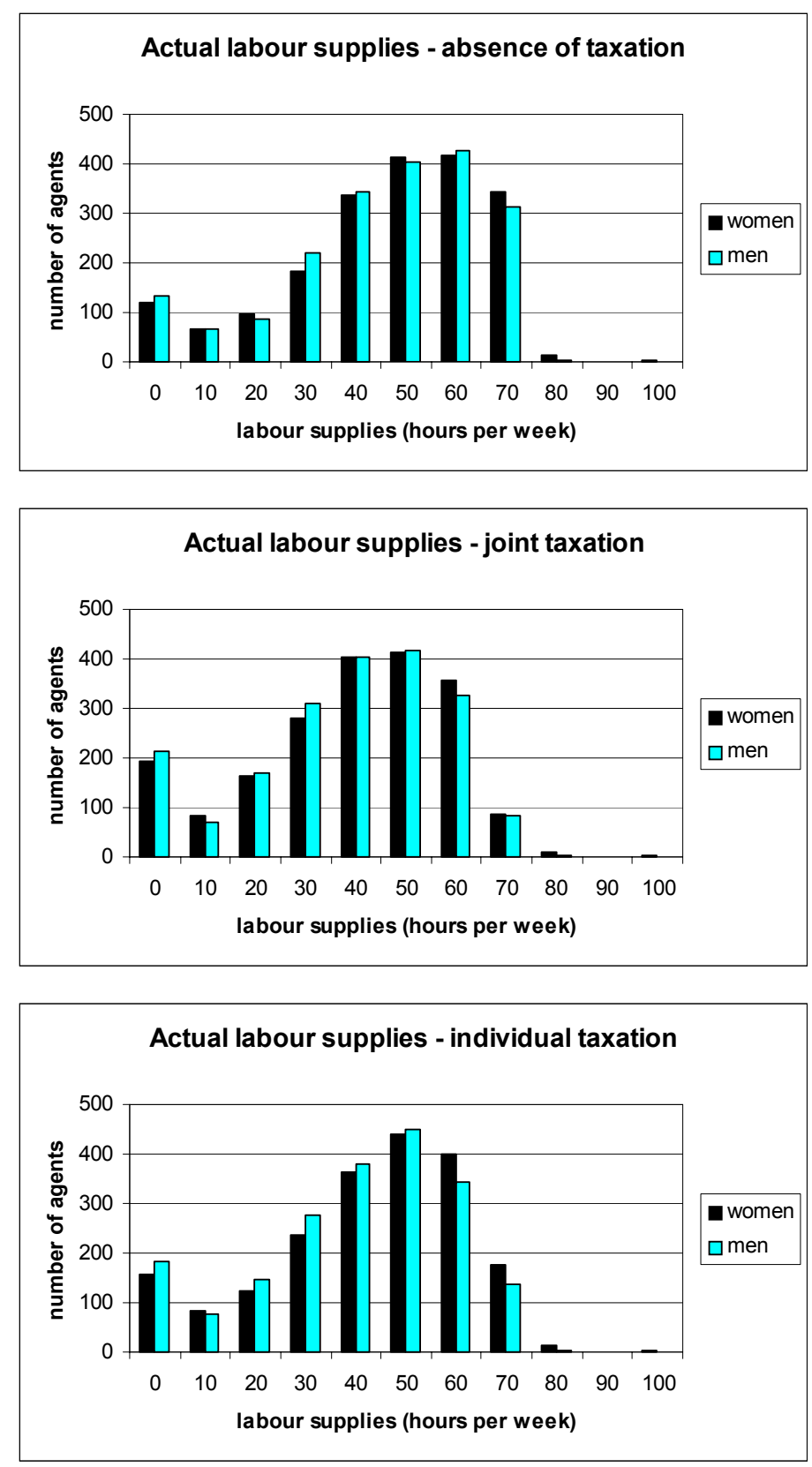

Figure 1: Weekly hours of work.

In the case of joint taxation the disincentive effect is even larger, and again, better endowed individuals are more affected. The new aspect here is that, in case of a large wage gap between the spouses, the poorer one will also reduce his or her labor supply: a comparatively low wage rate implies inequality on two accounts within the household: as regards wage income $w_{i}\left(T-l_{i}\right)$, and 
as regards the sharing of unearned income $y_{i}$. Joint taxation is relatively unfavorable to the less well endowed spouse, as the latter bears part of the tax burden of the richer spouse. Again, individuals with a high marginal propensity to consume are more affected than others.

The fact that joint taxation has a larger disincentive effect than individual taxation does not result from differences in tax revenue: the tax brackets have been specified in such a way that tax revenues are virtually identical in both situations (see Section 3 and Appendix D). In fact, it turns out that joint taxation is more favorable for households than individual taxation: for the tax parameters used here and for identical gross income (labor supplies and unearned income fixed), a couple pays more tax in the case of individual taxation than in the case of joint taxation (about $25 \%$ more). However, joint taxation is relatively more favorable to the richer spouse (see Section 6.4).

We now examine more specifically the impact of different variables and parameters on reactions to the introduction of one type of taxation or the other, and begin with household unearned income, $y$. As leisure is a normal good for each individual, leisure demand $l_{i}(i=f, m)$ will increase with $y$. However, in the case of joint taxation there are other effects at work, because there is a degree of interdependence in the behavior of the spouses. It then becomes difficult to say a priori what the impact of a change in $y$ will be.

The effect of a change in the wage rate $w_{i}$ on labor supply $h_{i}$ is even more ambiguous, as it depends on the other characteristics of the individual (marginal propensity to consume, spouse's wage and household unearned income). Yet our simulated data show generally a negative association between wages and labor supply. This is due to the fact that the income effect of a change in the wage is reinforced by the corresponding change in the individual's share of unearned income. In particular, individuals with the lowest wages often have a relatively high labor supply. Still, a clear effect is that an increase in $w_{i}(i=f, m)$ has a negative impact on the spouse's labor supply $h_{j}(j=f, m, j \neq i)$, because of the specification of the sharing rule (9).

Of course, an increase in the marginal propensity to consume $k_{i}$ induces individuals to work more.

The impact of changes in parameter values on $c_{i}$ are less ambiguous. There is a positive impact of $y, w_{i}$ and $k_{i}$ on $c_{i}$. By contrast, $w_{j}(j=f, m$, $j \neq i$ ) has a negative impact through the sharing rule. And, almost needless to say, introducing taxation has a negative effect on consumption. 


\section{$5 \quad$ Econometric specification of unitary model}

For the unitary model, we use the specification of van Soest (1995) and adopt his discrete choice approach, as this is well adapted to the estimation of preference parameters in the presence of non linear budget constraints. The household utility function has the direct translog form:

$$
\hat{U}(v)=v^{\prime} A v+b^{\prime} v
$$

where $v=\left(\log c, \log l_{f}, \log l_{m}\right) \equiv\left(l c, l l_{f}, l_{m}\right)$, and $\hat{U}($.$) represents the house-$ hold's utility function. The $3 \times 3$ matrix $A=\left(\left\{\alpha_{i j}\right\}\right), i, j=c, f, m$, is symmetric, and $b=\left(\left\{\beta_{i}\right\}\right)-i=c, f, m$, where $c, f, m$ are associated respectively to $l c, l l_{f}$ and $l l_{m}$ is a vector of parameters. Consumption $c$ results from the leisure choices through the budget constraint:

$$
c=g\left(l_{f}, l_{m}, w_{f}, w_{m}, y\right) .
$$

Moreover, we can add to the model some heterogeneity factors representing observed characteristics of the individual agents or the household. This inclusion of observable heterogeneity in the model will be done by allowing $b$ to depend linearly on observed characteristics. Here we will introduce only one type of observed heterogeneity, connected with the existence of three possible values for the marginal propensity to consume (see Appendix A). This will take the form of two series of three dummies, one for the wife, and one for the husband.

We assume that each individual has $n=11$ possible choices for his or her weekly labor supply: $h_{i}=T-l_{i}=0,10, \ldots, 100$. This yields a set of $N=121$ choices for the leisure demand pairs $\left(l_{f}, l_{m}\right)$ of the spouses. If $\hat{U}\left(l c^{j}, l l_{f}^{j}, l l_{m}^{j}\right)$ denotes the utility generated by combination $\left(c^{j}, l_{f}^{j}, l_{m}^{j}\right)$, adding an error term $\varepsilon_{j}$, we define actual utility derived from combination $j$ as:

$$
\hat{U}_{j}=\hat{U}\left(l c^{j}, l l_{f}^{j}, l l_{m}^{j}\right)+\varepsilon_{j} \quad \forall j=1, \ldots, N .
$$

Specifying the extreme value distribution for $\varepsilon_{j}$, defined by:

$$
\operatorname{Pr}\left[\varepsilon_{j}<\varepsilon\right]=\exp (-\exp (-\varepsilon)),
$$

leads to the multinomial logit model:

$$
\operatorname{Pr}\left[\hat{U}_{j}>\hat{U}_{k}, \forall k \neq j\right]=\frac{\exp \left(\hat{U}\left(c^{j}, l_{f}^{j}, l_{m}^{j}\right)\right)}{\sum_{k=1}^{N} \exp \left(\hat{U}\left(c^{k}, l_{f}^{k}, l_{m}^{k}\right)\right)} .
$$

Expression (17) represents the household's contribution to the likelihood. 
In the absence of unobserved heterogeneity in the data, there would only be marginal returns to the estimation of more refined specifications allowing for such heterogeneity, such as some version of the mixed multinomial of McFadden and Train (2000) or the heterogeneity augmented logit model of Chesher and Santos Silva (2002). Similarly, including fixed costs of work along the lines of Gong and van Soest (2002) would appear artificial, as no such costs are present in the data.

The following restrictions should be satisfied:

$$
-\hat{U}_{c}^{-1}\left(\begin{array}{lll}
c_{l_{f}} & 1 & 0 \\
c_{l_{m}} & 0 & 1
\end{array}\right) H \hat{U}\left(\begin{array}{ll}
c_{l_{f}} & c_{l_{m}} \\
1 & 0 \\
0 & 1
\end{array}\right)>0,
$$

where $\hat{U}_{x}=\frac{\partial \hat{U}}{\partial x}, c_{x}=-\frac{\hat{U}_{x}}{\hat{U}_{c}}, H \hat{U}=\left\{\hat{U}_{x, y}\right\}=\left\{\frac{\partial^{2} \hat{U}}{\partial x \partial y}\right\}$ with $x, y=c, l_{f}, l_{m}$. This restriction is a consequence of the quasi-concavity of the household utility function and of the fact that $\hat{U}$ is increasing in $c$ (see. e.g. van Soest et al., 1990). This last assumption is verified if:

$$
2\left(\alpha_{c c} l_{c}+\alpha_{f c} l_{f}+\alpha_{m c} l_{m}\right)+\beta_{c}>0 .
$$

Similar monotonicity restrictions apply w.r.t. the other arguments of $\hat{U}$.

\section{Results}

In this section we first give the estimation results for the unitary models, and the predictions of the labor supplies based on these estimates. We then perform the analysis of the different fiscal reforms, using the two type of models considered, and stress differences in positive and normative aspects of the corresponding evaluation.

\subsection{Estimation of unitary models}

Maximum likelihood estimates of the parameters of the utility function specified in Section 5, and based on equation (17), are given in Appendix C. Estimation was conducted in the three cases 'absence of taxation', 'joint taxation' and 'individual taxation', yielding three vectors of estimates denoted $\hat{\theta}^{o}, \hat{\theta}^{c}$ and $\hat{\theta}^{p}$, respectively. Following van Soest, we decided to interact the dummies describing the marginal propensity to consume of each spouse only 
with that individual's leisure demand. The estimates differ significantly. ${ }^{10}$ It is important to stress this point: as the individual underlying preferences are unchanged throughout this exercise, estimation results at the level of the household should in principle be fairly similar in all three situations. The fact that estimates for household preference parameters are affected by the form of the household budget constraint results solely from the misspecification embodied in the unitary representation of collective households.

The estimated coefficients $\beta_{i}, i=c, l_{f}, l_{m}$, differ considerably depending on the data set used - and thus on the tax system. The coefficients of leisure demand are all significant in one case only, that of individual taxation. The signs of significant $\beta$ coefficients for joint taxation agree with those for and individual taxation. But all significant $\beta$ coefficients for labor supply in the absence of taxation are positive, whereas they are negative for individual taxation. The coefficient $\hat{\beta}_{c}$ is strongly and significantly negative in all cases, but its magnitude doubles when going from absence of taxation to individual taxation, with the value for joint taxation in-between. Note that, even if the linear impact of consumption on utility (when the household is not taxed) is strongly negative, the overall effect of consumption on household utility is positive for almost all observations: condition (19) is satisfied, except for a few households where both spouses have a very large labor supply (connected with low wages and unearned income) especially in the case of individual taxation. The situation as regards labor supplies is less favorable, though.

Quadratic effects, both direct and cross effects, all significant in all three estimations, are a little more stable w.r.t. the tax system, as no sign reversals appear here. The direct effects (coefficients $\alpha_{i i}$ ) concerning leisure have similar magnitudes, although they are a little weaker in the case of individual taxation. Coefficient $\alpha_{c c}$ is more sensitive to the tax system, and the same holds for cross effects (coefficients $\alpha_{i j}$, with $i \neq j$ ), especially the cross effects consumption-leisure demand. Estimation results concerning the quadratic effects are fairly similar to those obtained with real data (see for example van Soest, 1995, for Dutch data, and Wolf, 1998, for German data). The restriction of quasi concavity of the utility function (18) is satisfied for most observations in each case.

\footnotetext{
${ }^{10}$ Admittedly, a more thorough comparison of estimation results could focus on marginal effects combining the linear and quadratic coefficients. However, the differences we note as large enough for us to dispense with that further step.
} 


\subsection{Predictions with unitary models}

These estimates can be used to make predictions of labor supplies, obtained by computing choice probabilities on the basis of equation (17) and taking the category with the highest choice probability as the chosen one.
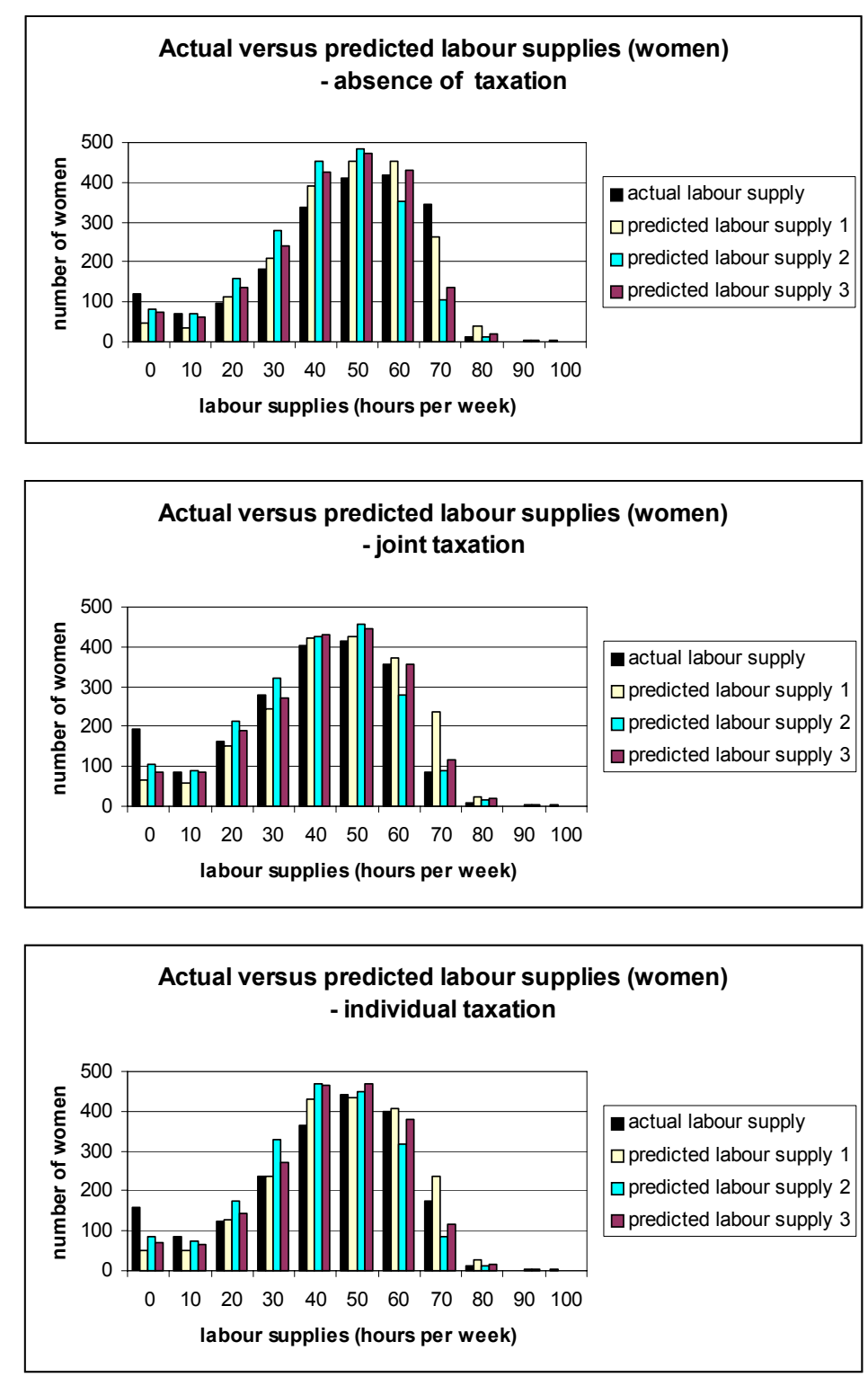

Figure 2: Actual and predicted weekly hours of work.

Note: predicted labor supplies 1,2 and 3 correspond to the use of parameter vectors $\hat{\theta}^{o}, \hat{\theta}^{c}$ and $\hat{\theta}^{p}$, respectively. 
Predicted labor supplies have a lower dispersion than effective labor supplies, and a more symmetric distribution (see Figures 2 for women; similar results are obtained for men). ${ }^{11}$ In particular the number of non-working individuals is under-estimated in all cases and for all predictions. The estimation of household labor supply on the basis of real-world data (see for instance van Soest, 1995) also indicates an over-estimation of the participation rates. Van Soest argues that this phenomenon may result from the endogeneity of wage rates and from characteristics of the demand side of the labor market, and proposes a correction taking account of restrictions on hours. But here wages are perfectly exogenous and known for all agents, and labor supply is not constrained in any way. Thus the over-estimation of participation rates does not result from the neglect of institutional factors in the specification.

Predictions obtained with estimated coefficients $\hat{\theta}^{c}$ and $\hat{\theta}^{p}$ tend to underestimate labor supplies (except predictions using $\hat{\theta}^{p}$ in the case of joint taxation). The under-estimation is larger when $\hat{\theta}^{c}$ is used. Predictions based on $\hat{\theta}^{o}$ over-estimate part-time work and under-estimate 'overtime'. Yet all vectors $\hat{\theta}$ are meant to estimate the same preference parameters, and predictions obtained with these vectors should not be too dissimilar.

The predictions look better when the coefficient vector used corresponds to the situation described (for example using $\hat{\theta}^{c}$ to predict labor supplies in the case of joint taxation), in the sense that more agents have identical predicted and actual labor supplies .

\subsection{Analysis of fiscal reforms: positive aspects}

Tables 2 and 3 show that the adjustment of labor supplies following the introduction of taxation is also poorly predicted using the unitary model, especially in the case of joint taxation. For example, with the unitary model at least 110 women are predicted to offer unchanged numbers of hours, whereas they actually reduce their weekly labor supply by 10 hours or more after the introduction of joint taxation, and more women are predicted to keep their labor supply unchanged than is actually the case (see Table 2). The reduction in hours offered after the introduction of any type of taxation is underestimated by the unitary models.

Tables 2 and 3 also show that predictions obtained with coefficients $\hat{\theta}^{c}$ and $\hat{\theta}^{p}$ are sightly worse than those obtained with $\hat{\theta}^{o}$, especially when $\hat{\theta}^{p}$ is used to predict the effect of introducing joint taxation and $\hat{\theta}^{c}$ is used for individual taxation.

\footnotetext{
${ }^{11}$ In the comparisons, we have discretised the collective labour supplies.
} 
Table 2: Effect of the introduction of joint taxation unitary versus collective model (women)

\begin{tabular}{llllll}
\hline \hline & $\leq-30$ & -20 & -10 & 0 & total \\
\hline-10 & 3 & 43 & $\mathbf{4 0 6}$ & 143 & 595 \\
0 & 10 & 106 & 718 & $\mathbf{5 6 2}$ & 1396 \\
10 & 0 & 4 & 0 & 5 & 9 \\
\hline total & 13 & 153 & 1124 & 710 & 2000 \\
\hline \multicolumn{5}{c}{ 1. using estimates $\hat{\theta}^{o}$}
\end{tabular}

\begin{tabular}{llllll}
\hline \hline & $\leq-30$ & -20 & -10 & 0 & total \\
\hline$\leq-10$ & 3 & 49 & $\mathbf{3 8 1}$ & 111 & 545 \\
0 & 10 & 96 & 738 & $\mathbf{5 9 1}$ & 1435 \\
$\geq 10$ & 0 & 8 & 5 & 7 & 20 \\
\hline total & 13 & 153 & 1124 & 710 & 2000 \\
\hline \multicolumn{5}{c}{2}
\end{tabular}

2. using estimates $\hat{\theta}^{c}$

\begin{tabular}{llllll}
\hline \hline & $\leq-30$ & -20 & -10 & 0 & total \\
\hline$\leq-10$ & 6 & 38 & $\mathbf{3 4 7}$ & 110 & 501 \\
0 & 7 & 109 & 770 & $\mathbf{5 8 9}$ & 1475 \\
$\geq 10$ & 0 & 6 & 7 & 11 & 24 \\
\hline total & 13 & 153 & 1124 & 710 & 2000 \\
\hline \multicolumn{5}{c}{ 3. using estimates $\hat{\theta}^{p}$}
\end{tabular}

Notes: columns show the actual change in labor supply when joint (resp. individual) taxation is introduced, rows show corresponding predicted changes using the unitary model, in the three versions $\hat{\theta}^{o}, \hat{\theta}^{c}$ and $\hat{\theta}^{p}$. Diagonal in bold. 
Table 3: Effect of the introduction of individual taxation unitary versus collective model (women)

\begin{tabular}{llllll}
\hline \hline & -20 & -10 & 0 & 10 & total \\
\hline-10 & 19 & $\mathbf{2 0 9}$ & 184 & 2 & 414 \\
0 & 44 & 473 & $\mathbf{1 0 1 0}$ & 0 & 1527 \\
10 & 2 & 3 & 54 & $\mathbf{0}$ & 59 \\
\hline total & 65 & 685 & 1248 & 2 & 2000 \\
\hline
\end{tabular}

1. using estimates $\hat{\theta}^{o}$

\begin{tabular}{llllll}
\hline \hline & -20 & -10 & 0 & 10 & total \\
\hline-10 & 18 & $\mathbf{2 1 2}$ & 139 & 1 & 370 \\
0 & 47 & 465 & $\mathbf{1 0 2 8}$ & 1 & 1541 \\
$\geq 10$ & 0 & 8 & 81 & $\mathbf{0}$ & 89 \\
\hline total & 65 & 685 & 1248 & 2 & 2000 \\
\hline \multicolumn{5}{c}{2}
\end{tabular}

2. using estimates $\hat{\theta}^{\mathrm{C}}$

\begin{tabular}{llllll}
\hline \hline & -20 & -10 & 0 & 10 & total \\
\hline-10 & 19 & $\mathbf{2 0 5}$ & 117 & 2 & 343 \\
0 & 45 & 468 & $\mathbf{1 0 0 0}$ & 0 & 1513 \\
$\geq 10$ & 1 & 12 & 131 & $\mathbf{0}$ & 144 \\
\hline total & 65 & 685 & 1248 & 2 & 2000 \\
\hline \multicolumn{5}{c}{ 3. using estimates $\hat{\theta}^{p}$}
\end{tabular}

Notes: columns show the actual change in labor supply when joint (resp. individual) taxation is introduced, rows show corresponding predicted changes using the unitary model, in the three versions $\hat{\theta}^{o}, \hat{\theta}^{c}$ and $\hat{\theta}^{p}$. Diagonal in bold.

\subsection{Analysis of fiscal reforms: normative aspects}

We begin with the tax reform analysis based on the collective model. Figures 3.1 and 3.2 show the distribution of individual welfare gains, here negative, by decile of the distribution of gross income in the baseline situation without taxation. As expected in the absence of redistribution of tax revenues, the introduction of taxation has a negative impact on welfare. Yet agents with low incomes do not incur losses when individual taxation is introduced, as they are not taxed at all. But some of them are affected by the introduction of joint taxation: their spouse is rich enough for the couple to be taxed. 
Figures 3.3 and 3.4 show the welfare consequences of the move from individual to joint taxation, for men and women. The fact that individual taxation is relatively more advantageous than joint taxation for low income individuals is confirmed. By contrast, high income agents are relatively better off with joint taxation, because it allows them to share the burden of taxation with the less well endowed spouse. Individual taxation is thus relatively more interesting for women, as their wage rates are on average $20 \%$ lower than men's.
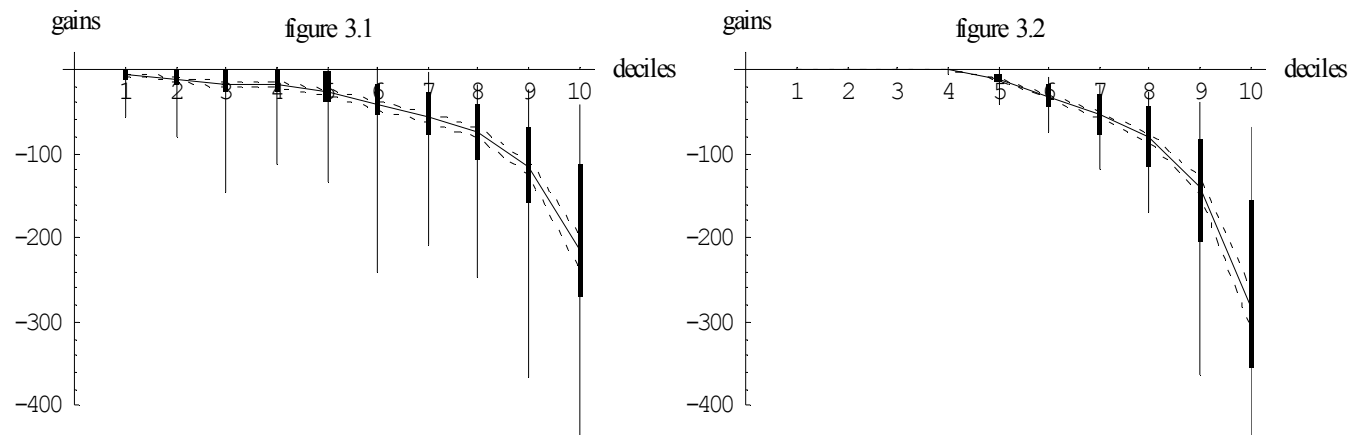

no tax $\rightarrow$ joint taxation (men)

no tax $\rightarrow$ individual taxation (men)
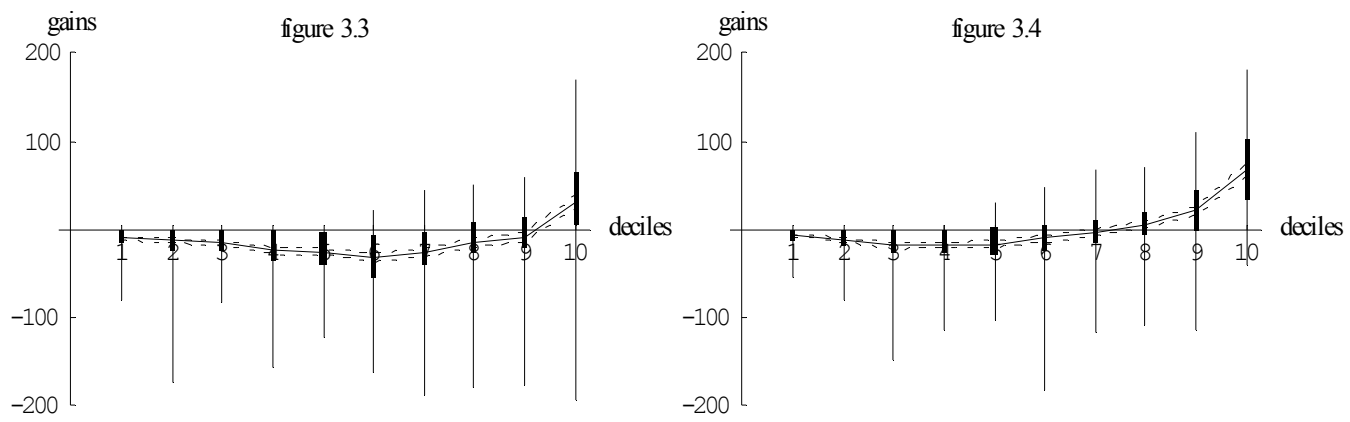

individual taxation $\rightarrow$ joint taxation women men

Figures 3: gains in individual utility for different fiscal reforms collective model

Notes: the figures represent mean utility gains by decile of the pre-reform gross individual income distribution for the introduction of joint taxation (Figure 3.1), individual taxation (Figure 3.2) and for the move from individual taxation to joint taxation (Figures 3.3 and 3.4), for women (Figure 3.3) and men (Figures 3.1, 3.2 and 3.4). The vertical lines show the range of gains, the rectangles show interquartiles intervals, the solid line shows average gains, and the dotted lines show confidence intervals ( \pm twice the standard error of the mean). 
Table 4 shows that in terms of welfare, $62 \%$ of the women gain in the move from joint to individual taxation, and some $20 \%$ are indifferent. The remaining $18 \%$ prefer joint taxation. By contrast, more men prefer joint taxation (about 36\%), 17\% are indifferent and the rest (47\%) gains from individual taxation.

Moreover, there are relatively few couples for which the direction of the relative advantage of each fiscal system is identical for both partners. This 'conflictual' situation is essentially due to the wage rate differential and the ensuing difference in incomes: the richer partner finds joint taxation advantageous. For only $42 \%$ of the couples both partners fall in the same category (winner, loser, indifferent) in the switch between the two systems. These are partly households whose members are indifferent to each tax system anyway, as their incomes are too low to be taxed.

Descriptive statistics on the subsamples of winners and losers (not shown here in order to gain space) indicate that the marginal propensity to consume has an important impact on the welfare effects of the fiscal systems. Winners from joint taxation have on average a higher marginal propensity to consume. By contrast, household unearned income has no notable impact on the relative advantage of one system over the other in terms of the sign of welfare changes.

We now turn to the welfare impact of the reforms as described on the basis of the unitary models. Figures 4 show the distribution of household utility gains by decile of the distribution of gross household income in the baseline situation without taxation, with utility gains computed from the unitary models. ${ }^{12}$ Results concerning the introduction of taxation (joint or individual) are not in conflict with those obtained with the collective representation of the household. However, results apparently diverge as regards the move from individual to joint taxation: whereas the richest individuals were mostly winners for the collective model, the majority of the richest households lose. This impression will be tempered when we look at individuals in households.

These results are described in Table 4, which compares the qualitative welfare effects (gain, loss, indifference) of the move from individual to joint taxation, and of the inverse move, as predicted by both models. Note that both panels of Table 4 are not exactly symmetrical: the number of households losing in the move from individual to joint taxation should in principle coincide with the number of winners in the reverse move, whatever the estimate $\hat{\theta}$ used. This asymmetry results from the more pronounced under-estimation of labor supplies with $\hat{\theta}^{c}$ than with $\hat{\theta}^{p}$. For about 100 households $(5 \%)$, the predicted qualitative welfare effects are contradictory, in the sense that, in

\footnotetext{
${ }^{12}$ The parameter used corresponds in each case to the initial tax system considered.
} 
the collective framework, at least one household member gains in a reform and the partner does not lose, whereas using the unitary model the household loses or is indifferent. For the majority of these, both spouses are indifferent to the reform, whereas the household appears to lose in the unitary framework: the discrepancy results from the poor quality of unitary predictions of labor supply responses.

The 'conflictual' situation uncovered by the collective model is masked by the unitary representation of household behavior. ${ }^{13}$ The relative advantage of a tax system in the collective model is essentially linked to the intra-familial income differential, and not only to total household income.
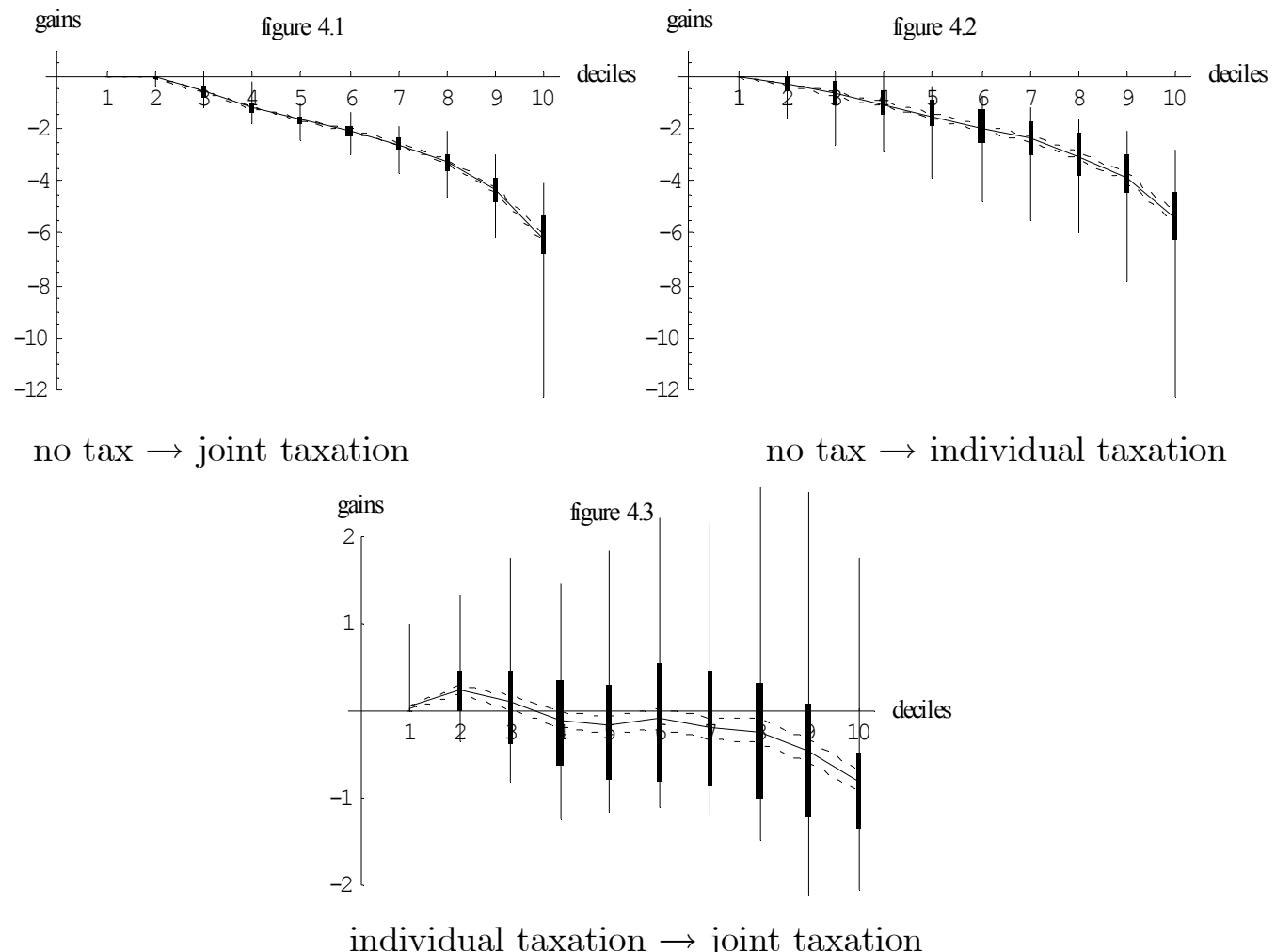

Figures 4: household utility gains

for different fiscal reforms, unitary model

Note: the figures represent household utility gains by decile of the distribution of pre-reform gross household income after the introduction of joint taxation (4.1), individual taxation (4.2) and in the move from individual to joint taxation (4.3).

\footnotetext{
${ }^{13}$ See also the simple example of Brett (1998) showing that Pareto improving reforms in a unitary setting are not necessarily Pareto improving in a collective setting (thanks to Frederic Vermeulen for drawing our attention to that reference).
} 
Table 4: Joint and individual taxation:

comparison of the collective and unitary models

\begin{tabular}{|c|c|c|c|c|c|c|c|c|c|c|}
\hline & \multicolumn{3}{|c|}{$f_{+}$} & \multicolumn{3}{|c|}{$f_{0}$} & \multicolumn{3}{|c|}{$f_{-}$} & \multirow[b]{2}{*}{ total } \\
\hline & $m_{+}$ & $m_{0}$ & $m_{-}$ & $m_{+}$ & $m_{0}$ & $m_{-}$ & $m_{+}$ & $m_{0}$ & $m_{-}$ & \\
\hline hous $_{+}$ & 5 & 33 & 217 & 51 & 49 & 1 & 377 & 2 & 3 & 738 \\
\hline hous $_{0}$ & 1 & 1 & 0 & 4 & 216 & 2 & 2 & 2 & 11 & 239 \\
\hline hous_- & 1 & 2 & 141 & 2 & 18 & 16 & 286 & 18 & 539 & 1023 \\
\hline \multirow[t]{3}{*}{ total } & 7 & 36 & 358 & 57 & 283 & 19 & 665 & 22 & 553 & 2000 \\
\hline & & $\overline{f_{-}}$ & & & $\overline{f_{0}}$ & & & 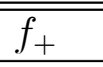 & & \\
\hline & $m_{-}$ & $m_{0}$ & $m_{+}$ & $m_{-}$ & $m_{0}$ & $m_{+}$ & $m_{-}$ & $m_{0}$ & $m_{+}$ & total \\
\hline hous_ & 5 & 30 & 214 & 46 & 39 & 1 & 387 & 3 & 3 & 728 \\
\hline hous $_{0}$ & 1 & 5 & 1 & 9 & 230 & 4 & 2 & 3 & 15 & 270 \\
\hline hous $_{+}$ & 1 & 1 & 143 & 2 & 14 & 14 & 276 & 16 & 535 & 1002 \\
\hline total & 7 & 36 & 358 & 57 & 283 & 19 & 665 & 22 & 553 & 2000 \\
\hline total $f$ & & 401 & & & 359 & & & 1240 & & 2000 \\
\hline total $m$ & $\overline{\left(m_{-}\right)}$ & 729 & & $\left(m_{0}\right)$ & 341 & & $\overline{\left(m_{+}\right)}$ & 930 & & 2000 \\
\hline
\end{tabular}

Notes: the first panel corresponds to the move from individual to joint taxation, the second panel to the inverse move. Rows: winning (hous + ), indifferent (hous ${ }_{0}$ ), and losing households (hous_) on the basis of coefficients estimated in the departure situation, i.e. $\hat{\theta}^{p}$ for the first panel and $\hat{\theta}^{c}$ for the second). Columns: winning females $\left(f_{+}\right)$and males $\left(m_{+}\right)$- resp. $f_{-}, m_{-}$and $f_{0}, m_{0}$ for losers or indifferent individuals, on the basis of the simulated collective data. 


\section{Conclusion}

On the basis of data simulated for 2000 collective households in three different fiscal situations, we have provided evidence on the distortions connected with the use of estimates from a unitary model for the evaluation of fiscal reforms.

Firstly, the unitary model leads to fairly diverging estimates of household 'preferences' depending on the budget constraint faced by the households; this is inasmuch problematic as these estimates are subsequently used as truly reflecting preferences.

Secondly, even using for each reform the unitary estimates corresponding to the departure situation, we find significant discrepancies in the prediction of positive effects of fiscal reforms (adjustment in the labor supplies of the spouses, and ex-ante computation of tax revenues). In particular, the latter point shows that using a unitary representation may lead to non-negligible errors in the design of revenue neutral reforms.

Finally, the comparison of the evaluation of welfare effects of fiscal reforms with the collective and unitary models reveals substantial divergences, but also points to the deep differences in their foundation itself. Using a unitary model leads the investigator to neglect resource allocations within the household, and this may mask the fact that a reform that seems advantageous for a majority of couples can in reality generate increased tensions and inequality within a substantial number of households. Symmetrically, using the collective model may lead to exaggerated emphasis on purely individual aspects.

An important development of this study, namely to generate data in a realistic way for different countries, taking account of the existing fiscal systems and reforms under discussion, as well as of the structure and the population, and to investigate how important the distortions illustrated here may be for these different countries, is documented in Laisney (2002). 


\section{References}

[1] Apps, P.F. and R. Rees (1988), Taxation and the Household, Journal of Public Economics, 35, 355-369.

[2] Apps, P.F. and R. Rees (1996), Labor Supply, Household Production and Intra-family Welfare Distribution, Journal of Public Economics, 60, 199-220.

[3] Apps, P.F. and R. Rees (1997), Collective Labor Supply and Household Production, Journal of Political Economy, 105, 178-190.

[4] Apps, P.F. and R. Rees (1999), Individual versus Joint Taxation in Models with Household Production, Journal of Political Economy, 107, 393-403.

[5] Arrow, K. (1951), Choix collectif et préférences individuelles, CalmannLévy, Paris.

[6] Becker, G.S. (1991), A Treatise on the Family, Harvard University Press.

[7] Beninger, D. (2000), Les modèles collectifs : introduction de la taxation, mimeo.

[8] Ben Porath, Y. (1982), Economics and the Family-Match or Mismatch: A Review of Becker's A Treatise on the Family, Journal of Economic Literature, 20, 52-64.

[9] Bergstrom, T.C. (1989), A Fresh Look at the Rotten Kid Theorem and other Household Mysteries, Journal of Political Economy, 97, 1138-1159.

[10] Blundell, R., P.-A. Chiappori, T. Magnac and C. Meghir (1998), Collective Labor Supply: Heterogeneity and Nonparticipation, Working Paper 20/98, Institute for Fiscal Studies, London.

[11] Bourguignon, F. (1999), The cost of children: may the collective approach to household behavior help?, Journal of Population Economics, $12,503-521$.

[12] Bourguignon, F., M. Browning, P.-A. Chiappori and V. Lechene (1994), Incomes and Outcomes: a Structural Model of Intra Household Allocations, Journal of Political Economy, 102, 1067-1096.

[13] Brett, C. (1998), Tax Reform and Collective family decision-making, Journal of Public Economics, 70, 425-440. 
[14] Browning, M. and P.-A. Chiappori (1998), Efficient Intra Household Allocations: a General Characterization and Empirical Tests, Econometrica, 66, 1241-1278.

[15] Chesher, A. and J.M.C. Santos Silva (2002), Taste Variation in Discrete Choice Models, Review of Economic Studies, 69, 147-168.

[16] Chiappori, P.-A. (1988), Rational Household Labor Supply, Econometrica, 56, 63-89.

[17] Chiappori, P.-A. (1992), Collective Labor Supply and Welfare, Journal of Political Economy, 100, 437-467.

[18] Chiappori, P.-A. (1997), Introducing Household Production in Collective Models Labor Supply, Journal of Political Economy, 105, 191-208.

[19] Chiuri, M.C. (1999), Intra-Household Allocation of Time and Resources: Empirical Evidence on a Sample of Italian Households with Young Children, TMR Progress Report $n^{\circ}$ 5, Tilburg.

[20] Deaton, D.A. and J. Muellbauer (1980), Economics and Consumer Behavior, Cambridge University Press.

[21] Donni, O. (2000), Essais sur les modèles collectifs de comportement du ménage, Doctoral Dissertation, DELTA, Paris.

[22] Gong, X. and A. van Soest (2002), Family structure and female labour supply in Mexico City, Journal of Human Resources, 37, 163-191.

[23] Haddad, L. and R. Kanbur (1990), How serious is Neglect of Intrahousehold Inequality, Economic Journal 100, 65-81.

[24] Hildenbrand, W. (1994), Market Demand: Theory and Empirical Evidence, Princeton University Press.

[25] Hildenbrand, W. (1998), How relevant are specifications of behavioral relations on the micro-level for modelling the time path of the population?, European Economic Review 42, 437-458.

[26] Laisney, F. (2002, ed.), Welfare Analysis of Fiscal and Social Security Reforms in Europe: Does the Representation of Family Decision Processes Matter? Report on EU Project VS/2000/0776, DG Employment and Social Affairs. 
[27] Lechene, V. (1993), Représentation du ménage : essais en microéconomie théorique et appliquée, Doctoral Dissertation, EHESS, Paris.

[28] Lundberg, S.J., R.A. Pollak and T.J. Wales (1996), Do Husbands and Wives pool their Resources? Evidence from the United Kingdom Child Benefit, The Journal of Human Resources 32, 463-480.

[29] McDonald, J.B. (1984), Some Generalized Funnctions for the Size Distribution of Income, Econometrica, 52, 647-663.

[30] McFadden, D. and K. Train (2000), Mixed MNL Models for Discrete Response, Journal of Applied Econometrics, 15, 447-470.

[31] Samuelson P.A. (1956), Social Indifference Curves, Quaterly Journal of Economics, 70, 1-22.

[32] Sen, A.K. (1984), Economics ans the Family, in Resources, Values and Development, Harvard University Press, Cambridge, MA. and London, England.

[33] van Soest, A., I. Woittiez and A. Kapteyn (1990), Labor Supply, Income Taxes and Hours Restrictions in the Netherlands, Journal of Human Resources 25(3), 517-558.

[34] van Soest, A. (1995), Structural Models of Family Labor Supply: a discrete Choice Approach, Journal of Human Resources 30, 63-88.

[35] Vermeulen, F. (2002), Collective Household Models: Principles and Main Results, forthcoming in Journal of Economic Surveys.

[36] Wolf, E. (1998), Do Hours Restrictions Matter? A discrete Family Labor Supply Model with endogeneous Wages and Hours Restrictions, $Z E W$ Discussion Paper 98-44. 


\section{Appendix A: parameters and variables}

The parameter values are common to all individuals (like total available time, for instance), the variables are particular to each individual (like gross wage rates). In the latter case, the individual values result from i.i.d. sampling for each individual (for wage rates and for the marginal propensities to consume) and for each couple (unearned income).

\subsection{Parameters}

The fixed parameters, i.e. minimum consumption, $\bar{c}$, total time available, $T$, and maximal working time, $H$, are common to the whole population. All pertain to a week. Minimum consumption per week is set to $\bar{c}=200$ monetary units. ${ }^{14}$ Total time available, in hours, is the duration of a week minus the time devoted to biological needs (sleeping, eating, etc.): $T=$ 120 hours. This corresponds to the upper bound for leisure. The maximum duration of work is set to $H=100$ hours. Note that we do not consider any domestic production in this model.

\subsection{Variables}

As mentioned above, these are the wage rates, unearned incomes and marginal propensities to consume.

Wage distributions are highly skewed to the right, and extremely low wages are rare in the rich countries (see e.g. Hildenbrand, 1994 and 1998). With these characteristics in mind, we specify the following density for the wages: $:^{15}$

$$
f_{w_{i}}\left(w_{i}\right)=\frac{w_{i}}{d_{i}^{2}} \exp \left(-\frac{w_{i}}{d_{i}}\right) \mathbf{1}\left(w_{i} \geq 0\right) \quad \forall i=f, m .
$$

The corresponding cumulative probability function is:

$$
\begin{aligned}
F_{w_{i}}\left(w_{i}\right) & =\quad \mathbf{1}\left(w_{i} \geq 0\right) \int_{0}^{w_{i}} \frac{t}{d_{i}^{2}} \exp \left(-\frac{t}{d_{i}}\right) d t \\
& =\mathbf{1}\left(w_{i} \geq 0\right)\left[1-\left(\frac{w_{i}}{d_{i}}+1\right) \exp \left(-\frac{w_{i}}{d_{i}}\right)\right]
\end{aligned}
$$

where $d_{f}=40$ and $d_{m}=50$. Expectation, standard error and mode are respectively $E\left(w_{i}\right)=2 d_{i}, \sigma\left(w_{i}\right)=d_{i} \sqrt{2}$, and $\operatorname{mode}\left(w_{i}\right)=d_{i}$. Figure A1 depicts the resulting wage distributions.

\footnotetext{
${ }^{14}$ We had French Francs per week in mind when setting monetary values, but the actual units really are irrelevant.

${ }^{15}$ This is a special case of the Fisk distribution (see e.g. McDonald, 1984).
} 


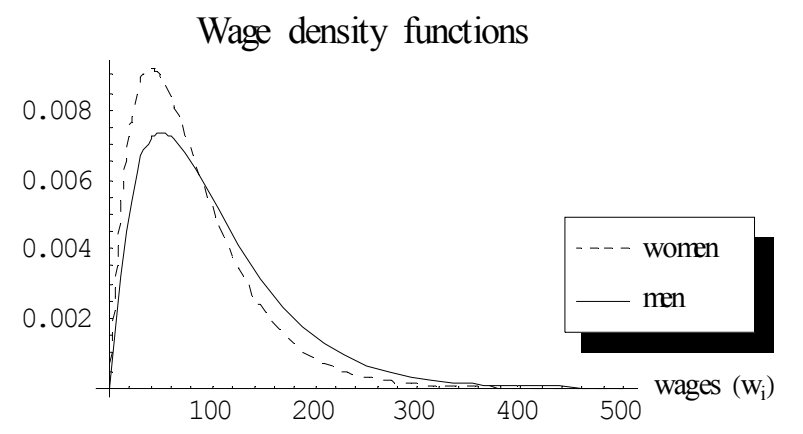

Figure A1: Wage densities for men and women.

For unearned income we assume the exponential distribution:

$$
f_{y}(y)=\frac{1}{\theta} \exp \left(-\frac{y}{\theta}\right) \mathbf{1}(y \geq 0)
$$

with $\theta=5000$. Expectation, standard error and mode are $E(y)=\sigma(y)=\theta$, and $\operatorname{mode}(y)=0$.

Individuals are assumed to have either a low marginal propensity to consume $\left(k_{i}=.4\right)$, or a medium one $\left(k_{i}=.5\right)$ or a high one $\left(k_{i}=.6\right)$. Define $\beta$ as a realization of the Beta distribution $B(2.6,2.6)$. We set:

$$
\begin{array}{ll}
k_{i}=.4 & \text { if } \beta \leq .4 \\
k_{i}=.5 & \text { if } .4<\beta<.5 \\
k_{i}=.6 & \text { if } \beta \geq .6
\end{array}
$$

These choices result in about a third of observations in each category, and $E\left(k_{i}\right)=\operatorname{mode}\left(k_{i}\right)=.5$, and $\sigma\left(k_{i}\right)=.08$. The dummies $\iota_{i 1}, \iota_{i 2}$ and $\iota_{i 3}$ take value 1 if $k_{i}=.4, .5$ or .6 , respectively, and 0 otherwise. 


\section{Appendix B: simulated data}

Table A1: simulation results - no taxation

\begin{tabular}{|c|c|c|c|c|}
\hline variable & mean & s.d. & min. & max. \\
\hline \multicolumn{5}{|c|}{ exogenous variables } \\
\hline$w_{f}$ & 77.3 & 55.0 & 2.0 & 425.3 \\
\hline$w_{m}$ & 102.3 & 71.3 & 2.8 & 440.8 \\
\hline$y_{f}$ & 2,205 & 2,711 & 1 & 20,627 \\
\hline$y_{m}$ & 2,850 & 3,706 & 1 & 52,56 \\
\hline$y$ & 5,055 & 5,460 & 2 & 56,310 \\
\hline \multicolumn{5}{|c|}{ choice variables, no taxation } \\
\hline$c_{f}$ & 5,972 & 4,115 & 218 & 29,931 \\
\hline$c_{m}$ & 7,758 & 5,331 & 291 & 52,567 \\
\hline$c$ & 13,730 & 6,404 & 1,863 & 56,310 \\
\hline$h_{f}$ & 46.8 & 19.7 & 0 & 100 \\
\hline$h_{m}$ & 45.8 & 19.6 & 0 & 89 \\
\hline$l_{f}$ & 73.2 & 19.7 & 20 & 120 \\
\hline$l_{m}$ & 74.2 & 19.6 & 31 & 120 \\
\hline \multicolumn{5}{|c|}{ choice variables, joint tax. } \\
\hline$c_{f}$ & 4,693 & 2,856 & 218 & 18,134 \\
\hline$c_{m}$ & 6,001 & 3,474 & 281 & 31,829 \\
\hline$c$ & 10,694 & 3,665 & 1,863 & 34,095 \\
\hline$h_{f}$ & 39.6 & 19.6 & 0 & 100 \\
\hline$h_{m}$ & 38.6 & 19.4 & 0 & 89 \\
\hline$l_{f}$ & 80.4 & 19.6 & 31 & 120 \\
\hline$l_{m}$ & 81.4 & 19.4 & 20 & 120 \\
\hline \multicolumn{5}{|c|}{ choice variables, ind. tax. } \\
\hline$c_{f}$ & 4,977 & 2,684 & 218 & 17,106 \\
\hline$c_{m}$ & 6,049 & 3,132 & 291 & 29,784 \\
\hline$c$ & 11,026 & 3,906 & 1,863 & 33,527 \\
\hline$h_{f}$ & 42.8 & 19.8 & 0 & 100 \\
\hline$h_{m}$ & 40.7 & 19.6 & 0 & 89 \\
\hline$l_{f}$ & 77.2 & 19.8 & 20 & 120 \\
\hline$l_{m}$ & 79.3 & 19.6 & 31 & 120 \\
\hline
\end{tabular}




\section{Appendix C: estimation of unitary model}

Table C1: estimation results - no taxation coefficient vector $\hat{\theta}^{o}$

\begin{tabular}{llrrr}
\hline \hline & parameter & coef. & s.e. & $\mathrm{t}$ \\
\hline$\beta_{f \iota_{f 1}}$ & $\left(\log l_{f} \times \iota_{f 1}\right)$ & 23.22 & 5.72 & 4.1 \\
$\beta_{f \iota_{f 2}}$ & $\left(\log l_{f} \times \iota_{f 2}\right)$ & 15.56 & 5.69 & 2.7 \\
$\beta_{f \iota_{f 3}}$ & $\left(\log l_{f} \times \iota_{f 3}\right)$ & 7.24 & 5.61 & 1.3 \\
$\beta_{m \iota_{m 1}}$ & $\left(\log l_{m} \times \iota_{m 1}\right)$ & 14.30 & 6.58 & 2.2 \\
$\beta_{m \iota_{m 2}}$ & $\left(\log l_{m} \times \iota_{m 2}\right)$ & 5.15 & 6.53 & .8 \\
$\beta_{m \iota_{m 3}}\left(\log l_{m} \times \iota_{m 3}\right)$ & -3.40 & 6.49 & -.5 \\
$\beta_{c}$ & $(\log c)$ & -49.92 & 10.76 & -4.7 \\
\hline$\alpha_{f f}$ & $\left(\log l_{f} \times \log l_{f}\right)$ & -17.59 & .57 & -31.0 \\
$\alpha_{m m}$ & $\left(\log l_{m} \times \log l_{m}\right)$ & -18.04 & .61 & -29.8 \\
$\alpha_{c c}$ & $(\log c \times \log c)$ & 1.51 & .42 & 3.6 \\
$\alpha_{f m}$ & $\left(\log l_{f} \times \log l_{m}\right)$ & 25.39 & .81 & 31.4 \\
$\alpha_{f c}$ & $\left(\log l_{f} \times \log c\right)$ & 3.45 & .44 & 7.9 \\
$\alpha_{m c}$ & $\left(\log l_{m} \times \log c\right)$ & 5.23 & .52 & 10.1 \\
\hline
\end{tabular}

Table C2: estimation results - joint taxation coefficient vector $\hat{\theta}^{c}$

\begin{tabular}{llrrr}
\hline \hline & parameter & coef. & s.e. & $\mathrm{t}$ \\
\hline$\beta_{f_{f 1}}$ & $\left(\log l_{f} \times \iota_{f 1}\right)$ & -13.42 & 4.60 & -2.9 \\
$\beta_{f \iota_{f 2}}$ & $\left(\log l_{f} \times \iota_{f 2}\right)$ & -20.80 & 4.59 & -4.5 \\
$\beta_{f \iota_{f 3}}$ & $\left(\log l_{f} \times \iota_{f 3}\right)$ & -28.86 & 4.50 & -6.4 \\
$\beta_{m \iota_{m} 1}$ & $\left(\log l_{m} \times \iota_{m 1}\right)$ & 4.45 & 5.26 & .8 \\
$\beta_{m \iota_{m} 2}$ & $\left(\log l_{m} \times \iota_{m 2}\right)$ & -4.18 & 5.19 & -.8 \\
$\beta_{m \iota_{m 3}}$ & $\left(\log l_{m} \times \iota_{m 3}\right)$ & -12.47 & 5.13 & -2.4 \\
$\beta_{c}$ & $(\log c)$ & -68.71 & 2.45 & -28.0 \\
\hline$\alpha_{f f}$ & $\left(\log l_{f} \times \log l_{f}\right)$ & -19.02 & .64 & -29.5 \\
$\alpha_{m m}$ & $\left(\log l_{m} \times \log l_{m}\right)$ & -20.17 & .70 & -28.8 \\
$\alpha_{c c}$ & $(\log c \times \log c)$ & 1.64 & .07 & 25.1 \\
$\alpha_{f m}$ & $\left(\log l_{f} \times \log l_{m}\right)$ & 30.80 & .96 & 32.1 \\
$\alpha_{f c}$ & $\left(\log l_{f} \times \log c\right)$ & 6.39 & .33 & 19.6 \\
$\alpha_{m c}$ & $\left(\log l_{m} \times \log c\right)$ & 5.95 & .37 & 15.9 \\
\hline
\end{tabular}


Table C3: estimation results - individual taxation coefficient vector $\hat{\theta}^{p}$

\begin{tabular}{llrrr}
\hline \hline & parameter & coef. & s.e. & $\mathrm{t}$ \\
\hline$\beta_{f \iota_{f 1}}$ & $\left(\log l_{f} \times \iota_{f 1}\right)$ & -17.97 & 4.79 & -3.7 \\
$\beta_{f \iota_{f 2}}$ & $\left(\log l_{f} \times \iota_{f 2}\right)$ & -24.59 & 4.81 & -5.1 \\
$\beta_{f \iota_{f 3}}$ & $\left(\log l_{f} \times \iota_{f 3}\right)$ & -31.44 & 4.77 & -6.6 \\
$\beta_{m \iota_{m} 1}$ & $\left(\log l_{m} \times \iota_{m 1}\right)$ & -21.06 & 5.32 & -4.0 \\
$\beta_{m \iota_{m} 2}$ & $\left(\log l_{m} \times \iota_{m 2}\right)$ & -28.93 & 5.31 & -5.4 \\
$\beta_{m \iota_{m 3}}$ & $\left(\log l_{m} \times \iota_{m 3}\right)$ & -36.50 & 5.30 & -6.9 \\
$\beta_{c}$ & $(\log c)$ & -91.34 & 3.50 & -26.1 \\
\hline$\alpha_{f f}$ & $\left(\log l_{f} \times \log l_{f}\right)$ & -13.80 & .52 & -26.6 \\
$\alpha_{m m}$ & $\left(\log l_{m} \times \log l_{m}\right)$ & -15.01 & .58 & -25.7 \\
$\alpha_{c c}$ & $(\log c \times \log c)$ & 2.35 & .09 & 26.5 \\
$\alpha_{f m}$ & $\left(\log l_{f} \times \log l_{m}\right)$ & 21.23 & .73 & 29.2 \\
$\alpha_{f c}$ & $\left(\log l_{f} \times \log c\right)$ & 6.22 & .44 & 14.1 \\
$\alpha_{m c}$ & $\left(\log l_{m} \times \log c\right)$ & 8.14 & .49 & 16.6 \\
\hline
\end{tabular}




\section{Appendix D: tax revenue}

The first column of Table $\mathrm{C}$ shows the amount of tax revenue in the situations of joint and individual taxation, computed from the simulated data. The small discrepancy between both figures could of course be eliminated by adjusting, say, the tax brackets in the joint taxation situation. However the subsequent columns show that this is of minor importance. For each estimated parameter vector and for each fiscal system, we report the tax revenue associated with the predicted labor market situation of each household. The misspecification associated with the unitary representation leads to important discrepancies. In all cases the unitary model predicts substantially larger tax revenues for joint taxation, whereas the actual tax revenue is actually marginally lower than for individual taxation. This point is important, because the evaluation of fiscal reforms often entails the specification of revenue neutral reforms.

The fact that the worst predictions are obtained using $\hat{\theta}^{o}$ is not surprising, since the introduction of taxation leads to large adjustments in labor supplies. However it is slightly puzzling to find that the revenue for individual tax is better predicted using $\hat{\theta}^{c}$ than $\hat{\theta}^{p}$. No such reversal appears for joint taxation. Another puzzle lies in the fact that tax revenues predicted using $\hat{\theta}^{c}$ and $\hat{\theta}^{p}$ are larger than the actual tax revenue, since the unitary model leads to an underestimation of labor supplies (see Section 6.2). In fact. low levels of labor supply are rather over-estimated and notably the number of participants is overstated. But individuals with low labor supply have on average higher unearned income and are thus more likely to be taxed.

Table C: tax revenues

\begin{tabular}{lrrrr}
\hline \hline model & collective & \multicolumn{3}{c}{ unitary } \\
tax system & & \multicolumn{1}{c}{$\hat{\theta}^{o}$} & $\hat{\theta}^{c}$ & \multicolumn{1}{c}{$\hat{\theta}^{p}$} \\
\hline joint taxation & $2,999,920$ & $4,096,180$ & $3,289,330$ & $3,490,220$ \\
individual taxation & $3,026,510$ & $3,801,910$ & $3,121,990$ & $3,324,170$ \\
variation & $-.88 \%$ & $+7.74 \%$ & $+5.36 \%$ & $+5.00 \%$ \\
\hline
\end{tabular}

